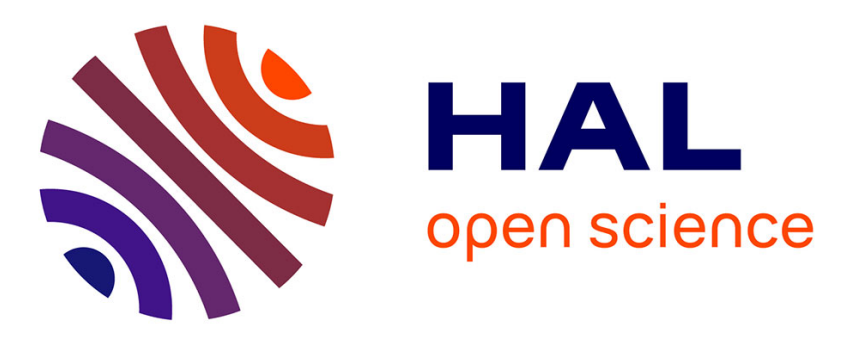

\title{
Role of dppf Monoxide in the Transmetalation Step of the Suzuki-Miyaura Coupling Reaction
}

Pierre-Adrien Payard, Antoine Bohn, Damien Tocqueville, Khaoula Jaouadi, Emile Escoude, Sanaa Ajig, Annie Dethoor, Geoffrey Gontard, Luca

Alessandro Perego, Maxime Vitale, et al.

\section{To cite this version:}

Pierre-Adrien Payard, Antoine Bohn, Damien Tocqueville, Khaoula Jaouadi, Emile Escoude, et al. Role of dppf Monoxide in the Transmetalation Step of the Suzuki-Miyaura Coupling Reaction. Organometallics, 2021, 10.1021/acs.organomet.1c00090 . hal-03201941

\section{HAL Id: hal-03201941 \\ https: / hal.sorbonne-universite.fr/hal-03201941}

Submitted on 19 Apr 2021

HAL is a multi-disciplinary open access archive for the deposit and dissemination of scientific research documents, whether they are published or not. The documents may come from teaching and research institutions in France or abroad, or from public or private research centers.
L'archive ouverte pluridisciplinaire HAL, est destinée au dépôt et à la diffusion de documents scientifiques de niveau recherche, publiés ou non, émanant des établissements d'enseignement et de recherche français ou étrangers, des laboratoires publics ou privés. 


\title{
On the Role of Dppf Monoxide in the Transmetalation step of the Su- zuki-Miyaura Coupling Reaction
}

\author{
Pierre-Adrien Payard, ${ }^{[\mathrm{a}]}, \dagger, *$ Antoine Bohn, ${ }^{[\mathrm{a}]}$ Damien Tocqueville, ${ }^{[\mathrm{a}]}$ Khaoula Jaouadi, ${ }^{[\mathrm{a}]}$ Emile Es- \\ coude, ${ }^{[\mathrm{a}]}$ Sanaa Ajig, ${ }^{[\mathrm{a}]}$ Annie Dethoor, ${ }^{[\mathrm{a}]}$ Geoffrey Gontard, ${ }^{[\mathrm{b}]}$ Luca Alessandro Perego, ${ }^{[\mathrm{c}]}$ Maxime Vi-

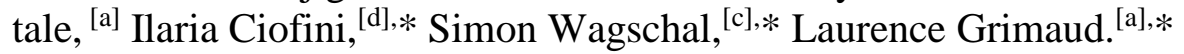

[a] Laboratoire des Biomolécules, LBM, Département de Chimie, École Normale Supérieure, PSL University, Sorbonne Université, CNRS, 75005 Paris, France. [b] Institut Parisien de Chimie Moléculaire, CNRS UMR 8232, Sorbonne Université, 4 Place Jussieu, 75252 Paris Cedex 05, France. [c] Discovery Product Development and Supply, Janssen Pharmaceutica, Hochstrasse 201, 8200 Schaffhausen (Switzerland). [d] PSL University, Institute of Chemistry for Health and Life Sciences, I-CLeHS, CNRS-Chimie ParisTech, 11 rue P. et M. Curie, F-75005 Paris 05 (France).

Suzuki Coupling $\bullet$ Palladium $\bullet$ Transmetalation $\bullet$ dppf $\bullet$ Diphosphine monoxide

\begin{abstract}
Diphosphine ligands are frequently used in palladium-catalyzed Suzuki-Miyaura (S-M) reactions. Despite their widespread application in both academic and industrial settings, their role in the B-to-Pd transmetalation has not been firmly established. We combined electrochemistry, NMR spectroscopy and DFT calculations to elucidate the role of dppf (1,1'-bis(diphenylphosphino)ferrocene) in this key elementary step of the S-M reaction. We observed that excess dppf inhibits transmetalation involving $\mathrm{PhB}(\mathrm{OH})_{2}$ and dppf-ligated arylpalladium(II) complexes, while an optimal $[$ base $] /\left[\mathrm{PhB}(\mathrm{OH})_{2}\right]$ ratio maximizes the concentration of a [Pd-O-B] key intermediate. In situ oxidation of dppf to the diphosphine monoxide dppfO can take place in the presence of base, leading to dppfO-ligated arylpalladium(II) complexes, which readily undergo transmetalation at room temperature. These findings suggest guidelines for the rational optimization of diphosphine-promoted S-M reactions.
\end{abstract}

The metal-catalyzed cross-coupling of organoboron derivatives with electrophiles, known as the Suzuki-Miyaura (S-M) reaction, has become one of the most important synthetic transformations in modern organic chemistry. ${ }^{1,2}$ It is widely applied on industrial scale to manufacture active pharmaceutical ingredients and fine chemicals. ${ }^{3}$ The mechanism of this reaction has been the subject of several experimental and theoretical studies. ${ }^{4,5,6,7}$ As displayed in Scheme 1, it is generally admitted to involve three elementary steps: an oxidative addition (OA), a transmetalation (TM), and a reductive elimination (RE). As it generally limits the rate of the overall cross-coupling process, the TM step has been the subject of several thorough mechanistic studies.

The TM can either proceed through the addition of the boronate $\left[\mathrm{Ar}^{\prime} \mathrm{B}(\mathrm{OH})_{3}\right]^{-}$to $\mathrm{OA}$ product ${ }^{5 \mathrm{~b}, 6 \mathrm{a}-\mathrm{d}, 6 \mathrm{~g}-\mathrm{k}}$ or from the association of the boronic acid with the Pd hydroxo complex (Scheme 1). ${ }^{5 \mathrm{~g}-\mathrm{i}, 51}$ The rate of this step can be finely tuned by the base/boronic acid ratio, ${ }^{5 \mathrm{~g}, 5 \mathrm{i}, 5 \mathrm{l}}$ and the Denmark group first gave experimental evidence of the key intermediate: the heterobimetallic [Pd-O-B] key species, which completed the description of the mechanistic scenario (Scheme 1). ${ }^{5 \mathrm{~b}, 5 \mathrm{n}, 5 \mathrm{o}, 5 \mathrm{q}}$

Diphosphines such as 1,1'-bis(diphenylphosphino)ferrocene (dppf), 1,2-bis(diphenylphosphino)ethane (dppe), and 1,3bis(diphenylphosphino)propane (dppp) are commonly used ligands in palladium-catalyzed Suzuki-Miyaura cross-couplings. ${ }^{1 \mathrm{k}}$ The mechanistic picture emerging form existing studies, which almost exclusively focus on monodentate phosphine ligands, is difficult to extend to chelating diphosphines in a straightforward manner.

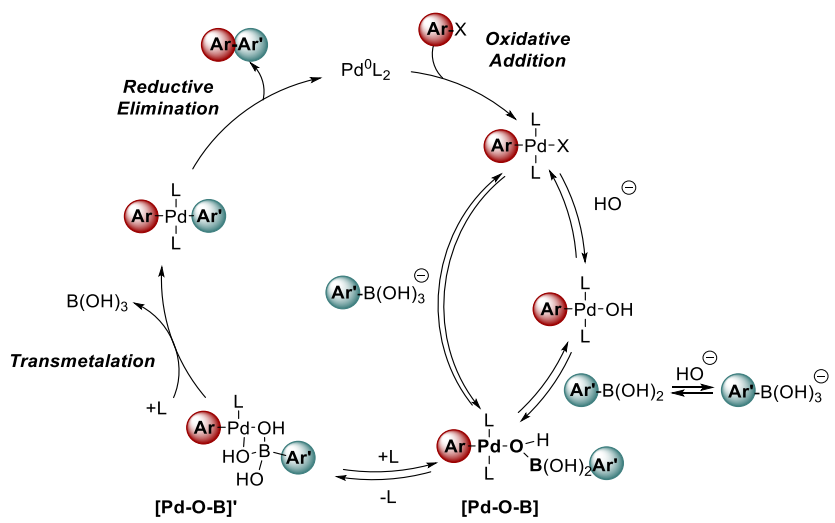

Scheme 1. General mechanism of the S-M cross-coupling reaction.

In particular, a mechanistic model should explain how bidentate ligands can accommodate the formation of the key [Pd-O-B] and [Pd-O-B]' species, both of which are necessary for the TM to occur according to the mechanism reported in Scheme 1. This issue has not been addressed systematically in the literature. Denmark and co-workers observed a slightly reduced transmetalation rate when dppf was employed instead of $\mathrm{PiPr}_{3}$, and conjectured the need of generating a coordinatively unsaturated intermediate, ${ }^{50}$ whose nature could not be firmly established. A theoretical study focusing on the S-M reaction promoted by complexes of the model ligand $\mathrm{H}_{2} \mathrm{PCH}_{2} \mathrm{CH}_{2} \mathrm{PH}_{2}$ investigated only an associative mechanism, for which very high energy barriers were computed. ${ }^{6 f}$ 
Suzuki-Miyaura Cross-Coupling

$$
\begin{gathered}
\begin{array}{c}
\text { Competent catalytic species } \\
\text { Hemilabile ligand } \\
\text { by dppf }
\end{array} \\
\text { Crition of } \mathrm{TM}
\end{gathered}
$$

Scheme 2. Hypothesis on the role of dppfO in S-M reactions proposed in this paper.

These two reports and the frequent use of diphosphine ligands in S-M cross-couplings prompted us to investigate the B-to-Pd transmetalation in the case of diphosphines. We observed that oxidation of dppf, a diphosphine widely used in S-M reactions applied to the total synthesis of natural products, ${ }^{1}$ could take place under conditions mimicking a typical catalytic reaction, yielding the monoxide dppfO. Our results highlight the potentially crucial role of this in situ generated species in diphosphine-mediated S-M reactions (Scheme 2). ${ }^{8}$

\section{Results and Discussion}

The oxidative addition complex cis-[Pd(Ar)Br(dppf)] (2, $\mathrm{Ar}=$ 4-F- $\mathrm{C}_{6} \mathrm{H}_{4}$ ) was prepared by ligand exchange between trans$\left[\mathrm{Pd}(\mathrm{Ar}) \mathrm{Br}\left(\mathrm{PPh}_{3}\right)_{2}\right](\mathbf{1})$ and dppf (Figure 1A) to study TM involving $\mathrm{PhB}(\mathrm{OH})_{2}$ using tetrabutylammonium hydroxide $(\mathrm{TBAOH})$ as a base.

\section{Inhibiting Effect of Extra Diphosphine on the TM}

We first investigated the effect of excess ligand on the B-to-Pd TM starting from either the OA complex 1 or $\mathbf{2}$ and different amounts of added $\mathrm{PPh}_{3}$ or dppf. The ratio $\left[\mathrm{OH}^{-}\right] /\left[\mathrm{PhB}(\mathrm{OH})_{2}\right] \approx$ 0.6 ( 6 equiv / 10 equiv) previously reported to maximize the TM rate in the case of $\mathrm{PPh}_{3}$-ligated complexes was used. ${ }^{5 \mathrm{~g}}$ Formation of the coupling product $\mathrm{Ar}-\mathrm{Ph}$ was monitored by ${ }^{19} \mathrm{~F}\left\{{ }^{1} \mathrm{H}\right\}$ NMR spectroscopy (Figure 1B). ${ }^{10}$

In the case of complex 1 in the presence of additional $\mathrm{PPh}_{3}(2$ equiv), the coupling reaction was almost complete after 5 min (Figure S5a). Formation of Ar-Ph followed a first order law with an apparent rate constant of $\left.k_{\text {app }}=3.310^{-3} \mathrm{~s}^{-1}\right) .^{5 \mathrm{~g}}$ No intermediate could be detected in this case, in agreement with TM being rate determining. ${ }^{5 \mathrm{~g}}$ In stark contrast, in the case of complex 2 , in the presence of 1 equiv of dppf (Figure 1B, green curve), TM is very slow and only $20 \%$ conversion was observed after $90 \mathrm{~min}$. Under these conditions, the kinetics could be fitted by a first order rate law and the apparent rate constant was estimated to be $k_{\text {app }}=3.210^{-5} \mathrm{~s}^{-1}$ (Figures S5). The ratio between the two rate constants is about 100 , which corresponds to a difference in activation energy of approximately $3 \mathrm{kcal} \mathrm{mol}^{-1}$. These observations indicate that dppf strongly inhibits B-to-Pd transmetalation. The TM turns out to be the second elementary step of the S-M reaction to be inhibited by excess dppf, as it has been shown that extra diphosphine also inhibits OA by hampering the formation of the reactive 14-electron complex $\left[\mathrm{Pd}^{0}(\mathrm{dppf})\right] .^{12}$

\section{A. Synthesis of Complex 2}
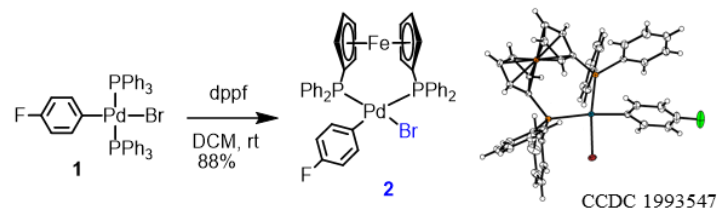

B. B-to-Pd Transmetalation on Complex 2 - dppf effect
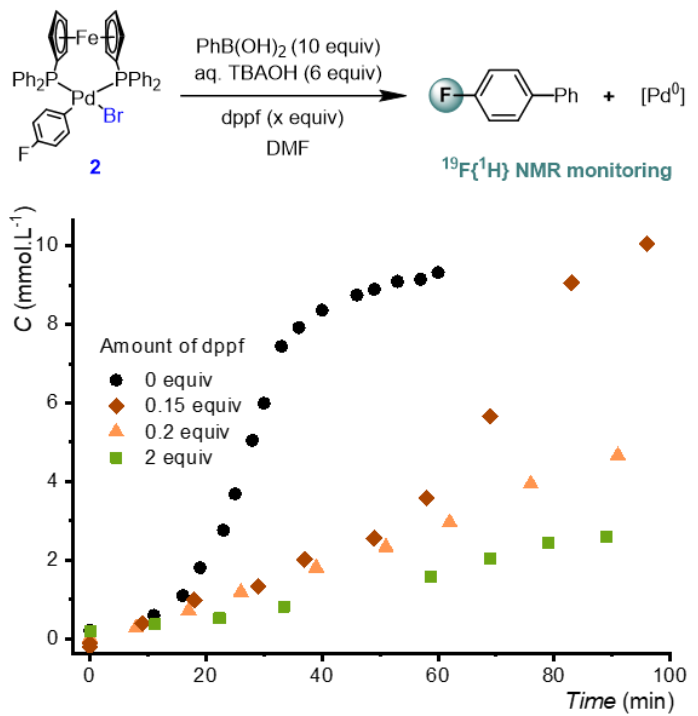

\section{DFT-calculated pathway for B-to-Pd Transmetalation on Complex 2}

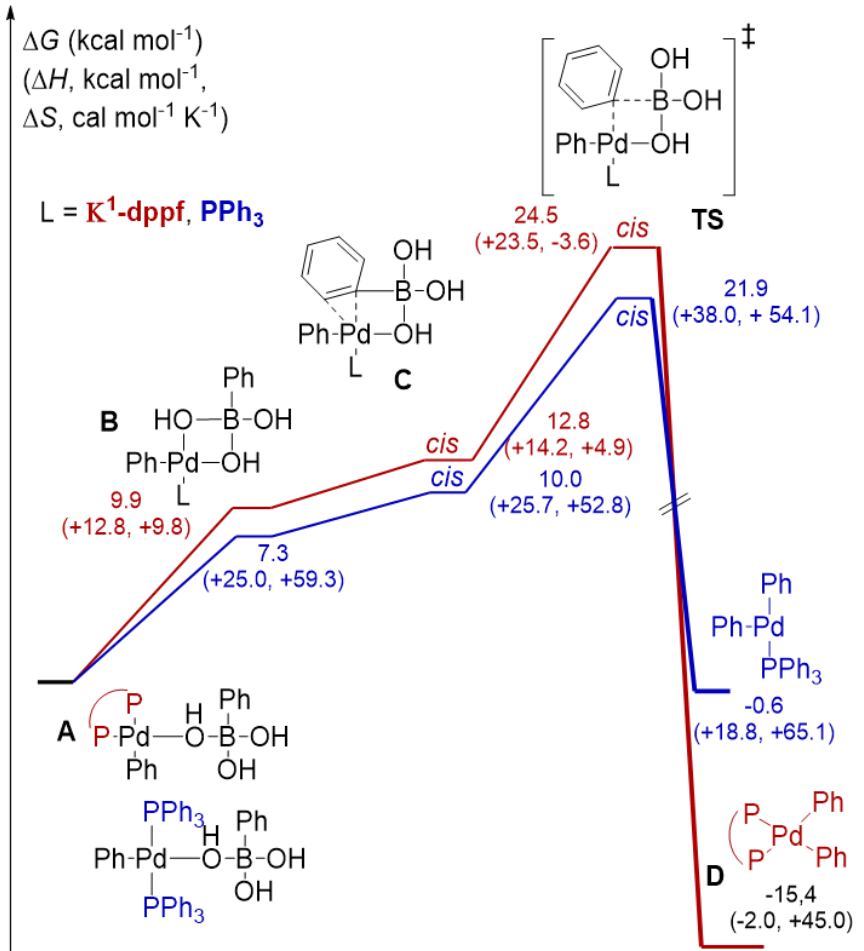

Figure 1. A. Synthesis of complex 2 by ligand exchange from 1. B. Reaction monitoring of the formation of 4-fluoro-1,1'-biphenyl from 2 $(20 \mathrm{mM}$ in $\mathrm{DMF})$ with $\mathrm{PhB}(\mathrm{OH})_{2}\left(10\right.$ equiv) and 6 equiv of $\mathrm{TBAOH}\left(1.5 \mathrm{M}\right.$ in $\left.\mathrm{H}_{2} \mathrm{O}\right)$ at $20^{\circ} \mathrm{C}$, in the presence of varying amounts of dppf. C. Most favored pathways for the TM and RE with dppf and $\mathrm{PPh}_{3}$ as ligands (see Figure $\mathrm{S} 4$ for the alternative trans pathway), studied by DFT calculations. Computed relative Gibbs free energies are reported in kcal mol ${ }^{-1}$ at $298 \mathrm{~K}$. Enthalpies $\left(\mathrm{kcal} \mathrm{mol}^{-1}\right)$ and entropies $\left(\mathrm{cal} \mathrm{K}^{-}\right.$ ${ }^{1} \mathrm{~mol}^{-1}$ ) are reported in parentheses. 
To rationalize these kinetic results, we estimated the energy barriers of the TM by DFT calculations (see the computational details in the Supporting Information) (Figures 1C and S6). The slower TM rate with dppf than that with $\mathrm{PPh}_{3}$ could possibly be due to a dissociative mechanism in contrast with the working hypothesis previously formulated by Huang et al. ${ }^{6 f}$ Indeed, as first demonstrated by Goossen and Thiel ${ }^{6 \mathrm{c}}$ the $\mathrm{TM}$ with $\mathrm{PPh}_{3^{-}}$ ligated $\mathrm{Pd}(\mathrm{II})$ requires partial phosphine decoordination and takes place via a four-centered transition-state involving the concerted formation of $\mathrm{Pd}-\mathrm{C}$ bond and cleavage of Pd-B bonds. Similar behavior is predicted for dppf (Figures 1C and S6).

Starting from complex [Pd-O-B] A, the cleavage of one P-Pd bond can be assisted by one $\mathrm{OH}$ of the boronate moiety to form complex $\mathbf{B}$. This release is endothermic $\left(+12.8 \mathrm{kcal} \mathrm{mol}^{-1}\right)$ and almost entropically neutral $\left(+9.8 \mathrm{cal} \mathrm{mol}^{-1} \mathrm{~K}^{-1}\right)$, leading to an overall endergonic process. For comparison, the same process involving $\mathrm{PPh}_{3}$ lies $2.6 \mathrm{kcal} \mathrm{mol}{ }^{-1}$ lower in energy $(+7.3 \mathrm{kcal}$ $\left.\mathrm{mol}^{-1}\right)$ driven by the strong positive entropic contribution $(+59.3$ cal $\mathrm{mol}^{-1} \mathrm{~K}^{-1}$ ). Nonetheless, complex $\mathbf{B}$ cannot directly take part into TM since the phenyl moiety on the boron center is too far from the Pd-center $\left(d_{(\mathrm{C}-\mathrm{Pd})}=3.42 \AA\right)$. Therefore, prior to $\mathrm{TM}$ a ligand exchange between the $\mathrm{OH}$ and $\mathrm{Ph}$ linked to the boron atom is thus required, leading to the formation of complex $\mathbf{C}$. Two pre-TM complexes C-cis $\left(+12.8 \mathrm{kcal} \mathrm{mol}^{-1}\right)$ and $\mathbf{C}$-trans $\left(+15.7 \mathrm{kcal} \mathrm{mol}^{-1}\right)$ can be formed depending on the relative position of the two aromatic rings with respect to the Pd-center. For clarity, in the main text and figures we will refer only to the most stable cis conformer, while all data corresponding to the trans conformer are available in the Supporting Information. In the case of dppf, both isomers are 4-5 $\mathrm{kcal} \mathrm{mol}^{-1}$ higher in free energy compared to the $\mathrm{PPh}_{3}$ analogues. Finally, both cis and trans transition states were optimized, lying at 24.5 and 27.5 $\mathrm{kcal} \mathrm{mol}^{-1}$ respectively. The energy barrier for phosphine decoordination directly impacts these transition states. In the case of $\mathrm{PPh}_{3}$, the most favourable TS-cis was localized at +21.9 $\mathrm{kcal} \mathrm{mol}^{-1}$, i.e. about $3 \mathrm{kcal} \mathrm{mol}^{-1}$ lower compared to dppf, corresponding roughly to a factor $10^{2}$ on the kinetics of the reaction. ${ }^{13}$ Both experimental and theoretical studies, thus, point towards a slower transmetalation rate when using diphosphine ligands. However, when the formation of the coupling product $\mathrm{Ar}-\mathrm{Ph}$ was monitored in the absence of added dppf, the reaction proceeded faster, and it was essentially complete after $30 \mathrm{~min}$ (Figure 1B, black curve). In the latter case, kinetic curve of formation of $\mathrm{Ar}-\mathrm{Ph}$ displayed an induction period, which is either typical of an autocatalytic reaction or hints at the in-situ generation of an active species from a less reactive precursor. ${ }^{11}$ The induction period varies from nearly $1 \mathrm{~h}$ at low base concentration to a few seconds at high base concentration (Figure S23). This is in agreement with the instantaneous reaction reported by Denmark and co-workers, ${ }^{5 \mathrm{n}}$ as the TM was studied starting from complex 3 with 1 equiv of boronic acid (corresponding to [ $\mathrm{OH}^{-}$ ]$\left./\left[\mathrm{PhB}(\mathrm{OH})_{2}\right]=1\right)$. Consistently with the concentration profiles (Figure 2C), this induction period probably results from the formation of a reactive species generated from either complex 3 or 4. To shed light on this surprising behavior, we investigated in more details the nature of potential intermediates of the dppfmediated S-M coupling.

\section{Intermediates of the TM Step}

When treated with $\mathrm{TBAOH}$ at $-20^{\circ} \mathrm{C}$, complex 2 , characterized by its reduction potential $\mathrm{R}_{2}$ at $-1.75 \mathrm{~V}$ vs $\mathrm{SCE}$ in DMF, evolved to a new complex with a reduction peak $\mathrm{R}_{3}$ at $-2.2 \mathrm{~V}$ (Figures $2 \mathrm{~A}$ and $\mathrm{S} 8$ ). This new peak was assigned to the corresponding hydroxo complex $[\mathrm{Pd}(\mathrm{Ar})(\mathrm{OH})(\mathrm{dppf})] \mathbf{3}$ and the structure was confirmed by ${ }^{31} \mathrm{P}\left\{{ }^{1} \mathrm{H}\right\}$ and ${ }^{19} \mathrm{~F}\left\{{ }^{1} \mathrm{H}\right\}$ NMR (Figures S9 to S11). ${ }^{50}$ While the hydroxo complex 3 was stable at $-20{ }^{\circ} \mathrm{C}$, it rapidly decomposed at room temperature in the absence of $\mathrm{PhB}(\mathrm{OH})_{2}$, thereby generating dppfO, as attested by $\mathrm{CV}$ showing the characteristic reduction peak of the latter compound $\left(\mathrm{R}_{5}\right.$ at $-2.46 \mathrm{~V}$ vs SCE, Figure 2D). At the same time, the formation of fluorobenzene and 4-fluoro-1,1'-biphenyl was also observed by ${ }^{19} \mathrm{~F}\left\{{ }^{1} \mathrm{H}\right\}$ NMR (Figures S10 and S24). In analogy with the welldescribed reduction of $\operatorname{Pd}(\mathrm{II})$ pre-catalysts in basic media, ${ }^{9}$ complex 3 probably evolved through a reductive elimination to give dppfO-ligated $\mathrm{Pd}(0)$ along with the protodemetalation product $\mathrm{ArH}$ and the homocoupling one Ar-Ar, which were detected by ${ }^{19} \mathrm{~F}\left\{{ }^{1} \mathrm{H}\right\}$ NMR (Figure 2D). ${ }^{14}$

When $\mathrm{PhB}(\mathrm{OH})_{2}$ was added to the in situ generated $[\mathrm{Pd}(\mathrm{Ar})(\mathrm{OH})(\mathrm{dppf})] 3$, a new reduction peak $\mathrm{R}_{4}$ was detected at $-2.09 \mathrm{~V}$ vs SCE (Figure 2A). The latter was attributed to the formation of the mixed complex [Pd-O-B] 4, in analogy with the data reported by the Denmark group as the ligand (Figures $\mathrm{S} 12$ to $\mathrm{S} 19) .{ }^{50}$ The ${ }^{31} \mathrm{P}\left\{{ }^{1} \mathrm{H}\right\}$ NMR titration of a solution containing complex 2 and 10 equiv of $\mathrm{PhB}(\mathrm{OH})_{2}$ with TBAOH demonstrated that the optimal $\left[\mathrm{OH}^{-}\right] /\left[\mathrm{PhB}(\mathrm{OH})_{2}\right]$ ratio is about $0.5-0.6$ so as to maximize the formation of the productive intermediate 4 (Figure 2B). Worthy of note, this optimal ratio can also vary depending on the quantity of boroxine present as an impurity in the boronic acid (Figures S20 and S21). ${ }^{4 b}$

The TM process was monitored by ${ }^{19} \mathrm{~F}\left\{{ }^{1} \mathrm{H}\right\}$ NMR using a ratio $\left[\mathrm{OH}^{-}\right] /\left[\mathrm{PhB}(\mathrm{OH})_{2}\right]=0.5$. Immediately after the addition of TBAOH, both 3 and $\mathbf{4}$ could be observed (Figure 2C, red curve) while some of the starting complex 2 remained (Figure $2 \mathrm{C}$, blue curve). After an induction period of about $25 \mathrm{~min}$, the crosscoupling product rapidly formed (Figure 2C, black curve). Interestingly, an additional intermediate $\mathrm{Pd}(\mathrm{II})$ complex $\mathbf{5}$ could be detected as a triplet at $-124.4 \mathrm{ppm}$ (Figure 2C, orange curve). Complex 5 accumulated during the reaction monitoring in parallel of a dramatic increase of the TM reaction rate (orange curve, Figure 2C). This behaviour seems to point out complex 5 as the active form of aryl-Pd toward transmetalation. 
A. Interaction between 2 and $\mathrm{PhB}(\mathrm{OH})_{3}{ }^{-}-\mathrm{CV}$<smiles>Fc1ccc([PH](Br)(c2ccccc2)c2ccccc2P(c2ccccc2)c2ccccc2)cc1</smiles>

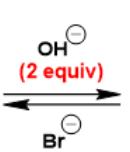

2

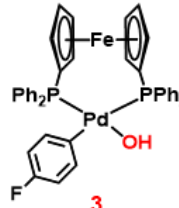

3
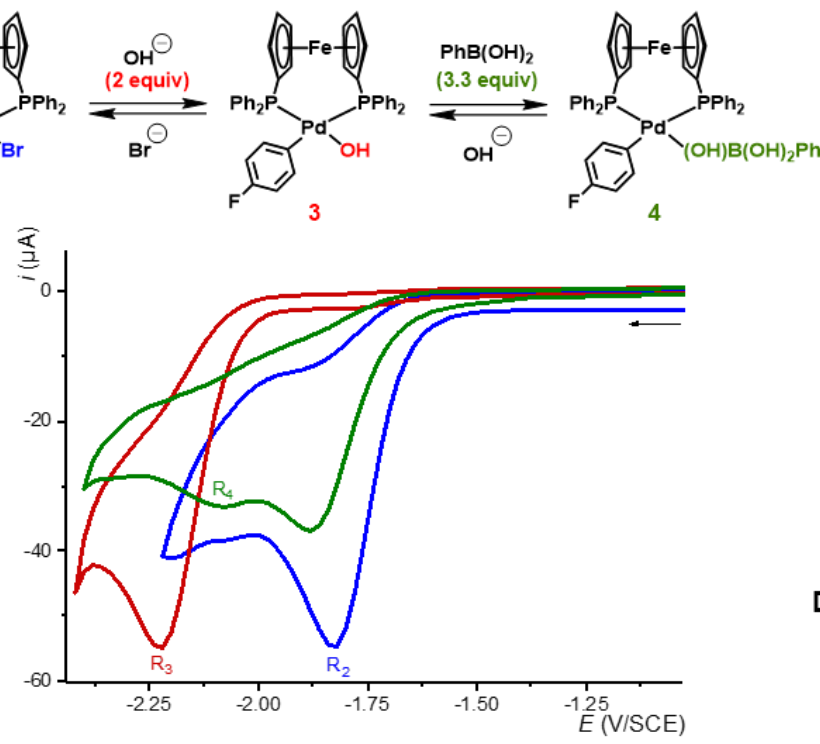

B. Interaction between 2 and $\mathrm{PhB}(\mathrm{OH})_{3}{ }^{-}-{ }^{31} \mathrm{P}$ NMR

2 equiv

D. Base catalyzed degradation of 2
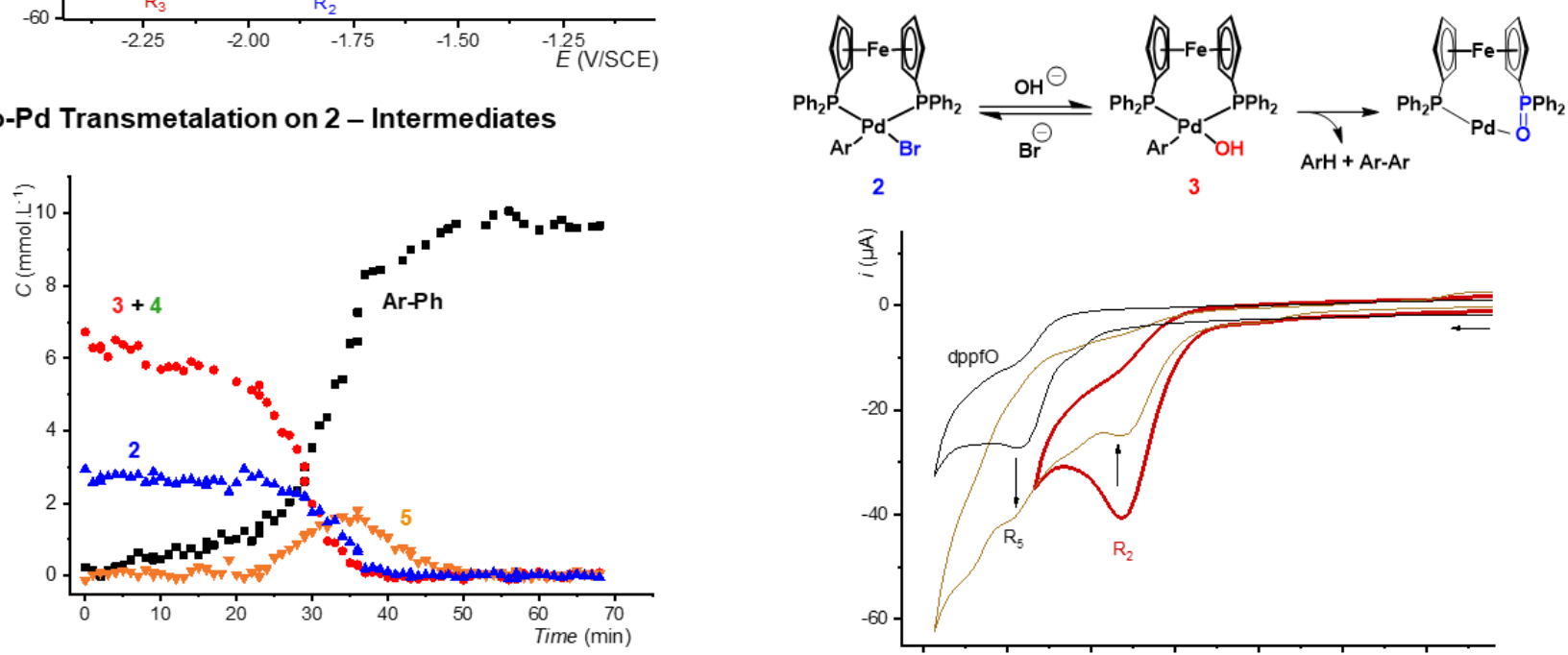

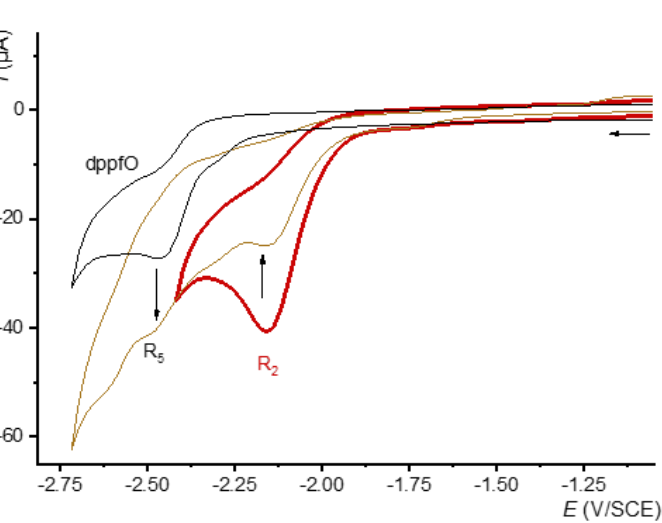

Figure 2. A. CV performed towards reduction potentials of a DMF solution containing $0.1 \mathrm{M}$ of $\mathrm{TBABF}_{4}$ at $-20{ }^{\circ} \mathrm{C}$, at a scan rate of $0.2 \mathrm{~V}$ $\mathrm{s}^{-1}$ with $2(2 \mathrm{mM})$ (blue), with 2 equiv of TBAOH $\left(1.5 \mathrm{M}\right.$ in $\left.\mathrm{H}_{2} \mathrm{O}\right)$ (red), after addition of $\mathrm{PhB}(\mathrm{OH})_{2}$ (3.3 equiv corresponding to a ratio [base]/[boronic acid] of 0.6) (green). B. ${ }^{31} \mathrm{P}\left\{{ }^{1} \mathrm{H}\right\}$ NMR of a solution of complex $2(20 \mathrm{mM})$ in DMF in the presence of $\mathrm{PhB}(\mathrm{OH})_{2}(10 \mathrm{equiv})$, upon increasing amount of TBAOH $\left(1.5 \mathrm{M}\right.$ in $\left.\mathrm{H}_{2} \mathrm{O}\right)$. A coaxial insert containing a solution of $\mathrm{H}_{3} \mathrm{PO}_{4}$ in DMSO- $d_{6}$ was used for locking and as an internal standard for integration. C. Reaction monitoring of complex $2(10 \mathrm{mM}$ in $\mathrm{DMF})$ with $\mathrm{PhB}(\mathrm{OH})_{2}(10$ equiv) in the presence of TBAOH (5 equiv) at $20{ }^{\circ} \mathrm{C}$, monitored by ${ }^{19} \mathrm{~F}\left\{{ }^{1} \mathrm{H}\right\}$ NMR. D. Formation of dppfO from 2 and 3 (Ar $\left.=4-\mathrm{F}-\mathrm{C}_{6} \mathrm{H}_{4}\right)$. CV performed towards reduction potentials of a DMF solution containing $0.1 \mathrm{M}$ of $\mathrm{TBABF}_{4}$ at rt, at a scan rate of $0.2 \mathrm{~V} \mathrm{~s}^{-1}$ with isolated complex 3 (2 mM (red), after 4 min (brown); CV of $2 \mathrm{mM}$ of isolated dppfO (black).

\section{Role of Diphosphine Monoxide dppfO}

To assess a potential catalytic role of dppfO or dppfO-ligated Pd species and shed light on the structure of complex 5, the TM in the presence of 0.15 equiv of dppfO was studied (Figure 3B, purple curve). An induction period similar to that observed in the absence of additives was found (Figure 3B, blue curve). Importantly, the effect of extra dppfO is less pronounced than that of dppf (Figure 3B, green curve). This suggests that the addition of dppfO alone does not lead to an active species. When introducing 0.1 equiv of $\operatorname{Pd}(\mathrm{dba})_{2}$ (with or without 0.1 equiv of dppfO, Figure 3B black and brown curves), no induction period could be detected and both reactions were complete within less than $20 \mathrm{~min}$. In both cases, the protodemetalation product $\mathrm{Ar}-\mathrm{H}$ and the homocoupling product Ar-Ar were observed, suggesting the concomitant decomposition of $\mathbf{3}$.

We hypothesized that the presence of $\operatorname{Pd}(0)$ promotes the $\mathrm{dppf} / \mathrm{dppfO}$ ligand exchange to form the less coordinated dppfO-ligated aryl $\mathrm{Pd}(\mathrm{II})$ complex. When adding in situ generated $\left[\mathrm{Pd}^{0}(\mathrm{dppfO})_{2}\right]$ (prepared by mixing $\mathrm{Pd}^{0}(\mathrm{dba})_{2}$ and dppfO, vide infra) to a DMF solution of complex 2 , the ${ }^{31} \mathrm{P}\left\{{ }^{1} \mathrm{H}\right\}$ spectrum was quite complex, most probably due to a rapid exchange of ligands on the NMR timescale, but the signal corresponding to complex 5 was clearly observed by ${ }^{19} \mathrm{~F}\left\{{ }^{1} \mathrm{H}\right\}$ NMR (Figure $\mathrm{S} 31$ ) and no induction period was apparent in this case (Figure 3B). This suggested that complex $\mathbf{5}$ is the active complex for $\mathrm{TM}$ and that it is formed in the presence of dppfO-ligated $\mathrm{Pd}^{0}$. 
A CV analysis of a mixture $\mathrm{Pd}(\mathrm{dba})_{2}$ with 2 equiv of dppfO demonstrated that a stoichiometric amount of dppfO was able to displace all the dba from the coordination sphere of $\operatorname{Pd}(0)$ (Figures S25 to S27), thus suggesting a strong affinity of dppfO for $\operatorname{Pd}(0)$. This contrasts with what was observed with dppf, since addition of 2 equiv of dppf on $\operatorname{Pd}(\mathrm{dba})_{2}$ resulted in the formation of the mixed complex $[\operatorname{Pd}(\mathrm{dba})(\mathrm{dppf})]$ (Figure S28) ${ }^{15}$ The resulting $\left[\mathrm{Pd}(\mathrm{dppfO})_{2}\right]$ was characterized for the first time by ${ }^{31} \mathrm{P}\left\{{ }^{1} \mathrm{H}\right\}$ NMR (Figure S29), and by $\mathrm{CV}$ (oxidation peak $\mathrm{O}_{1}$ at $+0.5 \mathrm{~V}$ vs SCE). This peak disappeared after addition of an excess of $4-\mathrm{F}-\mathrm{C}_{6} \mathrm{H}_{4} \mathrm{Br}$, confirming that this $\mathrm{Pd}(0)$ species is able to perform the initial OA step (Figure S30). ${ }^{16}$ $\left[\mathrm{Pd}(\mathrm{Ar}) \mathrm{Br}(\mathrm{dppfO})_{2}\right]$ could be prepared and characterized by ${ }^{1} \mathrm{H}$, ${ }^{13} \mathrm{C},{ }^{19} \mathrm{~F}\left\{{ }^{1} \mathrm{H}\right\}$ and ${ }^{31} \mathrm{P}\left\{{ }^{1} \mathrm{H}\right\}$ NMR and by ESI-MS (Figures $3 \mathrm{~A}$ and S3). Spectral data of this complex were identical to those of the previously observed complex $\mathbf{5}$ (vide supra, part 2), which kinetics data indicated as a crucial intermediate. When isolated complex 5 was treated with $\mathrm{PhB}(\mathrm{OH})_{2}$ and TBAOH no induction period was observed and the TM was completed within 10 min (Figures 3C and S32).

\section{A. Synthesis of 5}

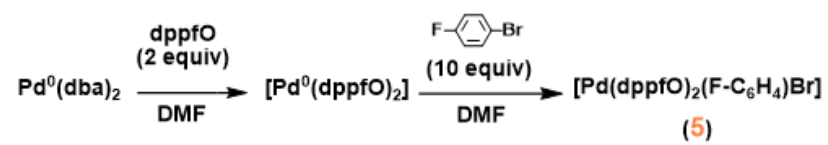

\section{DFT-calculated pathway for B-to-Pd Transmetalation on 5}

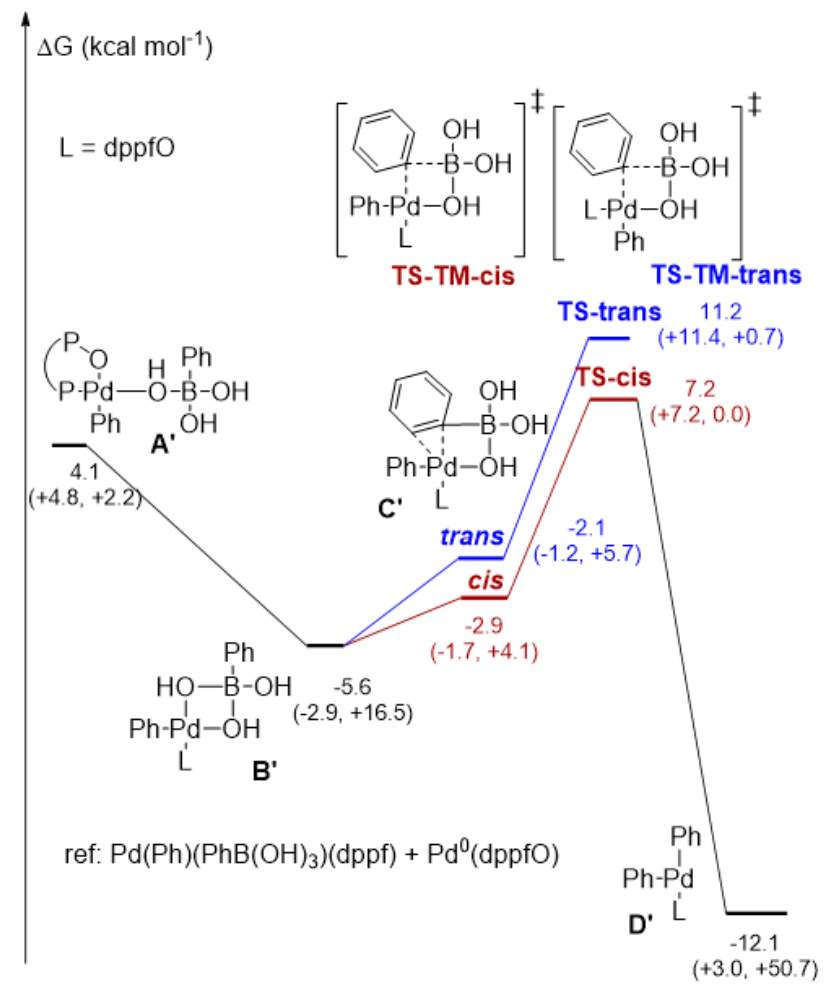

DFT calculations further confirmed that TM is favored with dppfO compared to TM with dppf (Figures 3D versus 1D). In agreement with the experimental results, the ligand exchange reaction between $[\mathrm{Pd}(\mathrm{dppfO})]$ and the dppf-ligated [Pd-O-B] to form dppfO-ligated complex $\mathbf{A}^{\prime}$ is only slightly endergonic $\left(+4.1 \mathrm{kcal} \mathrm{mol}^{-1}\right)$ and the formation of complex $\mathbf{B}$ ' is favored ($\left.9.7 \mathrm{kcal} \mathrm{mol}^{-1}\right)$. Coordination of the aromatic moiety to form complexes cis- or trans-C' is even more favorable and, as expected, the transition states for the TM step are very low lying $\left(+7.2\right.$ and $+11.2 \mathrm{kcal} \mathrm{mol}^{-1}$ for the cis and trans isomers respectively) accounting for the high activity of hemilabile-ligated $\mathrm{Pd}$ species for TM. Additionally, the RE step was also predicted to be faster with monocoordinated dppfO-ligated $\mathrm{Pd}$ species when compared to the dppf analogue (Figure S35).

\section{B. B-to-Pd transmetalation on in-situ generated 5}

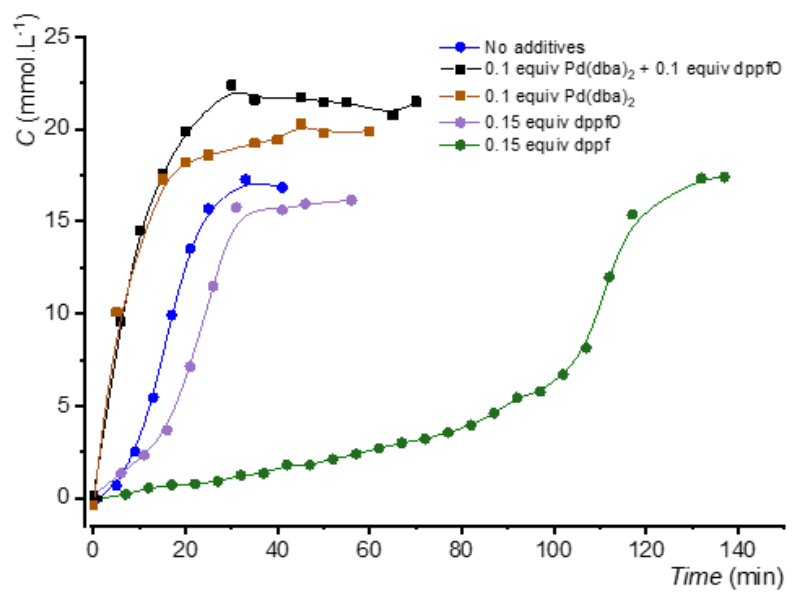

C. B-to-Pd transmetalation on 5

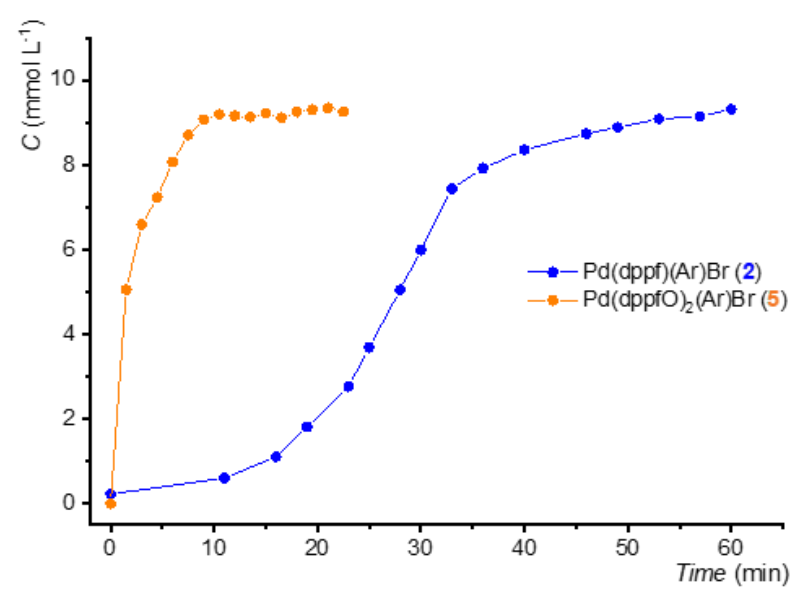

Figure 3. A. Oxidative addition with $\mathrm{Pd}^{0}(\mathrm{dppfO})_{2}$. B. ${ }^{19} \mathrm{~F}\left\{{ }^{1} \mathrm{H}\right\}$ NMR monitoring of the formation of 4-fluoro-1, $1^{\prime}$-biphenyl from 2 (20 mM in DMF) with 10 equiv of $\mathrm{PhB}(\mathrm{OH})_{2}$ and 6 equiv of TBAOH at $20{ }^{\circ} \mathrm{C}$. C. ${ }^{19} \mathrm{~F}\left\{{ }^{1} \mathrm{H}\right\}$ NMR monitoring of the formation of 4-fluoro-1, $1^{\prime}-$ biphenyl from 2 (blue, $10 \mathrm{mM}$ in DMF) and 5 (orange, $10 \mathrm{mM}$ in DMF), both with 10 equiv of $\mathrm{PhB}(\mathrm{OH})_{2}$ and 6 equiv of TBAOH at $20{ }^{\circ} \mathrm{C}$. D. Pathway for the TM process with dppfO as ligand studied by DFT calculations. Computed relative Gibbs free energies are reported in $\mathrm{kcal} \mathrm{mol}^{-1}$ at $298 \mathrm{~K}$. Enthalpies $\left(\mathrm{kcal} \mathrm{mol}^{-1}\right)$ and entropies $\left(\mathrm{cal} \mathrm{K}^{-1} \mathrm{~mol}^{-1}\right)$ are reported in parentheses. 


\section{Conclusions}

This work addressed three key points regarding the use of diphosphine ligands in the Suzuki-Miyaura reaction concerning: i) their effect on TM rate, ii) the need for decoordination prior TM, and iii) the possible inhibitory effects of diphosphine ligands. In the course of our study, we observed that TM involving $[\mathrm{PdArBr}(\mathrm{dppf})]$ and $\mathrm{PhB}(\mathrm{OH})_{2}$ in the presence of $\mathrm{OH}^{-}$proceeds with an induction period, suggesting that this complex needs to be converted to a more reactive species, which could be the actual intermediate of the catalytic cycle in S-M reactions. We have proved that dppf actually inhibits the TM and DFT calculations pointed out the need of partial decoordination of dppf for the TM to occur. Moreover, we showed that the dppfO generated from the in situ oxidation of dppf has a high affinity for $\mathrm{Pd}(0)$ species. $\mathrm{Pd}^{0}(\mathrm{dppfO})_{2}$ is able to perform oxidative addition to $\mathrm{ArBr}$ to give a dppfO-ligated aryl $\mathrm{Pd}(\mathrm{II})$, which in turn is very reactive in the TM with $\mathrm{PhB}(\mathrm{OH})_{2}$, as confirmed both experimentally and theoretically.

Finally, this study accounts for the widespread use of $\left[\mathrm{Pd}(\mathrm{dppf}) \mathrm{Cl}_{2}\right]$ as pre-catalyst for Suzuki-Miyaura cross-couplings, which is a direct precursor of dppfO-ligated $\operatorname{Pd}(0) .{ }^{9}$ The diphosphine ligand is required for the reduction of most commercially available $\mathrm{Pd}(\mathrm{II})$ pre-catalysts, ${ }^{9}$ but diphosphine monoxides could constitute efficient ligands to stabilize $\operatorname{Pd}(0)$ species and promote both the oxidative addition and the transmetalation steps.

\section{Experimental Section}

Synthesis of $\left[\mathrm{Pd}(\mathrm{dppfO})_{2}\left(4-\mathrm{F}-\mathrm{C}_{6} \mathrm{H}_{4}\right)(\mathrm{Br})\right](5)$. The reaction was carried out under argon. To a stirred mixture of $\left[\mathrm{Pd}(\mathrm{dba})_{2}\right](50$ $\mathrm{mg}, 0.087 \mathrm{mmol})$ in degassed $\mathrm{CH}_{2} \mathrm{Cl}_{2}(5 \mathrm{~mL})$ was added 1bromo-4-fluorobenzene $(95 \mu \mathrm{L}, 0.7 \mathrm{mmol})$ and 2.1 equiv of $\mathrm{dppfO}^{[17]}$ (104 mg, 0.18mmol). After vigorous stirring at ambient temperature (red-brown color), the flask was fitted with a reflux condenser and heated in an oil bath at $50{ }^{\circ} \mathrm{C}$ overnight. The reaction mixture was allowed to warm to room temperature, then the solution was evaporated to a volume of approx. 1 $\mathrm{mL}$ and treated with degassed petroleum ether $(5 \mathrm{~mL})$. The dark red precipitate was filtered under inert atmosphere, washed with petroleum ether and dried in vacuo to produce complex 5 (100 mg, 80\%). ${ }^{31} \mathrm{P}\left\{{ }^{1} \mathrm{H}\right\}$ NMR (121 MHz, DMF): $\delta=25.3$ (br s), $16.1\left(\mathrm{~d}, J_{\mathrm{P}^{-} \mathrm{F}}=3.0 \mathrm{~Hz}\right) \mathrm{ppm} .{ }^{19} \mathrm{~F}\left\{{ }^{1} \mathrm{H}\right\} \mathrm{NMR}(282 \mathrm{MHz}, \mathrm{DMF})$ : $\delta=-124.4\left(\mathrm{t}, J_{\mathrm{P}-\mathrm{F}}=3.0 \mathrm{~Hz}\right) \mathrm{ppm}$. MS $(\mathrm{ESI}+\mathrm{MeCN}) \mathrm{m} / \mathrm{z}(\%)$ : 1341.1 (100) [(M-Br $\left.)^{+}\right]$.

\section{Computational Details}

All DFT calculations were performed using the Gaussian 09 program (Rev. A02). ${ }^{9}$ The structure of all minima and transition states were optimized using the M06 functional ${ }^{10}$ and the following basis set: 6-31G for C, H, F, and B; 6-31+G(d) for O and P; LANL2DZ for Pd and Fe with the associated effective core potential LANL2. ${ }^{11}$ Bulk solvent effects were taken into account using the PCM method as implemented in Gaussian. ${ }^{12}$ The default cavity parameters, static and optical dielectric constants for DMF were used. The nature of all stationary points was checked by analytical frequency calculations. Computed harmonic frequencies were employed to calculate free energies at $298 \mathrm{~K}$ and $1 \mathrm{~atm}$ pressure with the usual approximations.

\section{ASSOCIATED CONTENT}

\section{Supporting Information}

Tables of experimental ${ }^{31} \mathrm{P}$ NMR chemical shifts and calculated shielding constants, additional data on the effect of computational parameters on structures and shielding constants. (PDF) Cartesian geometries and absolute energies. (xyz file)

The Supporting Information is available free of charge on the ACS Publications website.

\section{AUTHOR INFORMATION}

\section{Corresponding Authors}

*pierre-adrien.payard@univ-lyon1.fr; laurence.grimaud@ens.psl.eu; swagscha@its.jnj.com; ilaria.ciofini@chimieparis.psl.eu

\section{Present Addresses}

$\dagger$ Pierre-Adrien Payard - Univ Lyon, Université Claude Bernard Lyon I, CNRS, INSA, CPE, UMR 5246, ICBMS, 1 rue Victor Grignard, F-69622 Villeurbanne cedex, France.

The authors declare no competing financial interests.

\section{ACKNOWLEDGMENT}

P. A. Payard is grateful to ENS Paris Saclay and Solvay for a PhD grant. We acknowledge Dr D. Lesage for the mass spectrometry analyses. We thank Prof A. Boutin, P. J. Yao and Dr Q. Chen for useful discussions. We thank Janssen Pharmaceutica and BristolMyers Squibb for the funding the project.

\section{REFERENCES}

1.a) Miyaura, N.; Suzuki, A., Palladium-Catalyzed Cross-Coupling Reactions of Organoboron Compounds. Chem. Rev. 1995, 95, 2457-2483; b) Negishi, E.-i., Handbook of Organopalladium Chemistry for Organic Synthesis. John Wiley \& Sons, Inc.: New York, USA, 2002; c) Suzuki, A., Cross-coupling reactions via organoboranes. J. Organomet. Chem. 2002, 653, 83-90; d) Miyaura, N., Organoboron Compounds. In Cross-Coupling Reactions: A Practical Guide, Miyaura, N., Ed. Springer Berlin Heidelberg: Berlin, Heidelberg, 2002; pp 11-59; e) Tsuji, J., Palladium Reagents and Catalysts. 2004; f) de Meijere, A.; Diederich, F., Metal-Catalyzed CrossCoupling Reactions. Wiley-VCH Verlag GmbH: Weinheim, Germany, 2004; g) Bellina, F.; Carpita, A.; Rossi, R., Palladium Catalysts for the Suzuki Cross-Coupling Reaction: An Overview of Recent Advances. Synthesis 2004, 2004, 2419-2440; h) Martin, R.; Buchwald, S. L., Palladium-Catalyzed Suzuki-Miyaura Cross-Coupling Reactions Employing Dialkylbiaryl Phosphine Ligands. Acc. Chem. Res. 2008, 41, 1461-1473; i) Li, H.; Johansson Seechurn, C. C. C.; Colacot, T. J., Development of Preformed Pd Catalysts for Cross-Coupling Reactions, Beyond the 2010 Nobel Prize. ACS Catal. 2012, 2, 1147-1164; j) Johansson Seechurn, C. C. C.; Kitching, M. O.; Colacot, T. J.; Snieckus, V., Palladium-Catalyzed Cross-Coupling: A Historical Contextual Perspective to the 2010 Nobel Prize. Angew. Chem. Int. Ed. 2012, 51, 5062-5085; k) Rossi, R.; Bellina, F.; Lessi, M.; Manzini, C.; Marianetti, G.; Perego, L. A., Recent Applications of Phosphane-based Palladium Catalysts in Suzuki-Miyaura Reactions Involved in Total Syntheses of Natural Products. Curr. Org. Chem. 2015, 19 (14), 1302-1409; 1) Maluenda, I.; Navarro, O., Recent Developments in the Suzuki-Miyaura Reaction: 2010-2014. Molecules 2015, 20, 7528-7557.

2.a) Montgomery, J., Nickel-Catalyzed Reductive Cyclizations and Couplings. Angew. Chem. Int. Ed. 2004, 43 (30), 3890-3908; b) Han, F.-S., Transition-metal-catalyzed Suzuki-Miyaura cross-coupling reactions: a remarkable advance from palladium to nickel catalysts. Chem. Soc. Rev. 2013, 42 (12), 5270-5298; c) Yamaguchi, J.; Muto, K.; Itami, K., Recent Progress in Nickel-Catalyzed Biaryl Coupling. Eur. J. Org. Chem. 2013, 2013 (1), 19-30; d) Tasker, S. Z.; Standley, E. A.; Jamison, T. F., Recent advances in homogeneous nickel catalysis. Nature 2014, 509 (7500), 299309; e) Ananikov, V. P., Nickel: The "Spirited Horse" of Transition Metal Catalysis. ACS Catal. 2015, 5 (3), 1964-1971; f) Li, Z.; Liu, L., Recent advances in mechanistic studies on Ni catalyzed cross-coupling reactions. Chin. J. Catal. 2015, 36 (1), 3-14.

3.a) Magano, J.; Dunetz, J. R., Large-Scale Applications of Transition Metal-Catalyzed Couplings for the Synthesis of Pharmaceuticals Chem. Rev. 2011, 111, 3, 2177-2250; b) Ashworth, I. W.; Campbell, A. D.; Cherryman, J. H.; Clark, J.; Crampton, A.; Eden-Rump, E. G. B.; Evans, M.; Jones, M. F.; McKeever-Abbas, S.; Meadows, R. E.; Skilling, K.; 
Whittaker, D. T. E.; Woodward, R. L.; Inglesby, P. A., Process Development of a Suzuki Reaction Used in the Manufacture of Lanabecestat. Org. Process Res. Dev. 2018, 22 (12), 1801-1808; c) Maity, P.; Reddy, V. V. R.; Mohan, J.; Korapati, S.; Narayana, H.; Cherupally, N.; Chandrasekaran, S.; Ramachandran, R.; Sfouggatakis, C.; Eastgate, M. D.; Simmons, E. M.; Vaidyanathan, R., Development of a Scalable Synthesis of BMS-978587 Featuring a Stereospecific Suzuki Coupling of a Cyclopropane Carboxylic Acid. Org. Process Res. Dev. 2018, 22 (7), 888897; d) Schäfer, G.; Fleischer, T.; Ahmetovic, M.; Abele, S., Development of a Scalable Route for a Key Thiadiazole Building Block via Sequential Sandmeyer Bromination and Room-Temperature Suzuki-Miyaura Coupling. Org. Process Res. Dev. 2020, 24 (2), 228-234; e) Chen, C.-Y.; Dagneau, P.; Grabowski, E. J. J.; Oballa, R.; O'Shea, P.; Prasit, P.; Robichaud, J.; Tillyer, R.; Wang, X., Practical Asymmetric Synthesis of a Potent Cathepsin K Inhibitor. Efficient Palladium Removal Following Suzuki Coupling. J. Org. Chem. 2003, 68 (7), 2633-2638; f) Conlon, D. A.; Drahus-Paone, A.; Ho, G.-J.; Pipik, B.; Helmy, R.; McNamara, J. M.; Shi, Y.-S.; Williams, J. M.; Macdonald, D.; Deschênes, D.; Gallant, M.; Mastracchio, A.; Roy, B.; Scheigetz J., Process Development and LargeScale Synthesis of a PDE4 Inhibitor, Org. Process Res. Dev. 200610 (1), 36-45; g) Li, B.;.Buzon, R. A.; Zhang Z., Syntheses of 4,5-Disubstituted Oxazoles via Regioselective C-4 Bromination. Org. Process Res. Dev. 2007, 11 (6), 951-955; h) Keen, S. P.; Cowden, C. J.; Bishop, B. C.; Brands, K. M. J.; Davies, A. J.; Dolling, U. H.; Lieberman, D. R.; Stewart G. W., Practical Asymmetric Synthesis of a Non-Peptidic $\alpha_{v} \beta_{3}$ Antagonist. J. Org. Chem. 2005, 70 (5), 1771-1779.

4. For reviews dedicated to transmetalation see a) Partyka, D. V., Transmetalation of Unsaturated Carbon Nucleophiles from BoronContaining Species to the Mid to Late d-Block Metals of Relevance to Catalytic $\mathrm{C}-\mathrm{X}$ Coupling Reactions $(\mathrm{X}=\mathrm{C}, \mathrm{F}, \mathrm{N}, \mathrm{O}, \mathrm{Pb}, \mathrm{S}, \mathrm{Se}, \mathrm{Te})$. Chem. Rev. 2011, 111 (3), 1529-1595; b) Lennox, A. J. J.; Lloyd-Jones, G. C., Transmetalation in the Suzuki-Miyaura Coupling: The Fork in the Trail. Angew. Chem. Int. Ed. 2013, 52 (29), 7362-7370.

5. Experimental mechanistic studies about Pd-catalyzed S-M coupling: a) Aliprantis, A. O.; Canary, J. W., Observation of Catalytic Intermediates in the Suzuki Reaction by Electrospray Mass Spectrometry. J. Am. Chem. Soc. 1994, 116, 6985-6986; b) Matos, K.; Soderquist, J. A., Alkylboranes in the Suzuki-Miyaura Coupling: Stereochemical and Mechanistic Studies. J. Org. Chem. 1998, 63, 461-470; c) Adamo, C.; Amatore, C.; Ciofini, I.; Jutand, A.; Lakmini, H., Mechanism of the Palladium-Catalyzed Homocoupling of Arylboronic Acids: Key Involvement of a Palladium Peroxo Complex. J. Am. Chem. Soc. 2006, 128, 6829-6836; d) Nunes, C. M.; Monteiro, A. L., Pd-catalyzed Suzuki cross-Coupling reaction of bromostilbene: insights on the nature of the boron Species. J. Brazilian Chem. Soc. 2007, 18, 1443-1447; e) Sicre, C.; Braga, A. A. C.; Maseras, F.; Cid, M. M., Mechanistic insights into the transmetalation step of a Suzuki-Miyaura reaction of 2(4)-bromopyridines: characterization of an intermediate. Tetrahedron 2008, 64, 7437-7443; f) Butters, M.; Harvey, J. N.; Jover, J.; Lennox, A. J. J.; Lloyd-Jones, G. C.; Murray, P. M., Aryl Trifluoroborates in Suzuki-Miyaura Coupling: The Roles of Endogenous Aryl Boronic Acid and Fluoride. Angew. Chem. Int. Ed. 2010, 49, 51565160; g) Amatore, C.; Jutand, A.; Le Duc, G., Kinetic Data for the Transmetalation/Reductive Elimination in Palladium-Catalyzed SuzukiMiyaura Reactions: Unexpected Triple Role of Hydroxide Ions Used as Base. Chem. Eur. J. 2011, 17 (8), 2492-2503; h) Carrow, B. P.; Hartwig, J. F., Distinguishing Between Pathways for Transmetalation in Suzuki-Miyaura Reactions. J. Am. Chem. Soc. 2011, 133 (7), 2116-2119; i) Amatore, C.; Jutand, A.; Le Duc, G., Mechanistic Origin of Antagonist Effects of Usual Anionic Bases (OH-, CO32-) as Modulated by their Countercations $(\mathrm{Na}+, \mathrm{Cs}+, \mathrm{K}+)$ in Palladium-Catalyzed Suzuki-Miyaura Reactions. Chem. Eur. J. 2012, 18 (21), 6616-6625; j) Amatore, C.; Jutand, A.; Le Duc, G., The Triple Role of Fluoride Ions in Palladium-Catalyzed Suzuki-Miyaura Reactions: Unprecedented Transmetalation from [ArPdFL2] Complexes. Angew. Chem. 2012, 124, 1408-1411; k) Amatore, C.; Jutand, A.; Le Duc, G., The Triple Role of Fluoride Ions in PalladiumCatalyzed Suzuki-Miyaura Reactions: Unprecedented Transmetalation from [ArPdFL2] Complexes. Angew. Chem. Int. Ed. 2012, 51 (6), 13791382; 1) Amatore, C.; Le Duc, G.; Jutand, A., Mechanism of palladiumcatalyzed Suzuki-Miyaura reactions: multiple and antagonistic roles of anionic "bases" and their countercations. Chem. Eur. J. 2013, 19, 1008293; m) Fyfe, J. W. B.; Valverde, E.; Seath, C. P.; Kennedy, A. R.; Redmond, J. M.; Anderson, N. A.; Watson, A. J. B., Speciation Control During Suzuki-Miyaura Cross-Coupling of Haloaryl and Haloalkenyl MIDA Boronic Esters. Chem. Eur. J. 2015, 21, 8951-8964; n) Thomas, A. A.; Denmark, S. E., Pre-transmetalation intermediates in the Suzuki-
Miyaura reaction revealed: The missing link. Science 2016, 352, 329-332; o) Thomas, A. A.; Wang, H.; Zahrt, A. F.; Denmark, S. E., Structural, Kinetic, and Computational Characterization of the Elusive Arylpalladium(II)boronate Complexes in the Suzuki-Miyaura Reaction. $J$. Am. Chem. Soc. 2017, 139, 3805-3821; p) Kohlmann, J.; Braun, T.; Laubenstein, R.; Herrmann, R., Suzuki-Miyaura Cross-Coupling Reactions of Highly Fluorinated Arylboronic Esters: Catalytic Studies and Stoichiometric Model Reactions on the Transmetallation Step. Chem. Eur. J. 2017, 23, 12218-12232; q) Thomas, A. A.; Zahrt, A. F.; Delaney, C. P.; Denmark, S. E., Elucidating the Role of the Boronic Esters in the SuzukiMiyaura Reaction: Structural, Kinetic, and Computational Investigations. $J$ Am. Chem. Soc. 2018, 140 (12), 4401-4416.

6. Computational mechanistic studies about Pd-catalyzed S-M coupling: a) Goossen, L. J.; Koley, D.; Hermann, H. L.; Thiel, W., The PalladiumCatalyzed Cross-Coupling Reaction of Carboxylic Anhydrides with Arylboronic Acids: A DFT Study. J Am. Chem. Soc. 2005, 127 (31), 1110211114; b) Braga, A. A. C.; Morgon, N. H.; Ujaque, G.; Maseras, F., Computational Characterization of the Role of the Base in the Suzuki-Miyaura Cross-Coupling Reaction. J Am. Chem. Soc. 2005, 127 (25), 9298-9307; c) Goossen, L. J.; Koley, D.; Hermann, H. L.; Thiel, W., Palladium Monophosphine Intermediates in Catalytic Cross-Coupling Reactions: A DFT Study. Organometallics 2006, 25 (1), 54-67; d) Braga, A. A. C.; Ujaque, G.; Maseras, F., A DFT Study of the Full Catalytic Cycle of the Suzuki-Miyaura Cross-Coupling on a Model System. Organometallics 2006, 25 (15), 3647-3658; e) Lakmini, H.; Ciofini, I.; Jutand, A.; Amatore, C.; Adamo, C., Pd-Catalyzed Homocoupling Reaction of Arylboronic Acid: Insights from Density Functional Theory. $J$. Phys. Chem. A 2008, 112 (50), 12896-12903; f) Huang, Y.-L.; Weng, C.M.; Hong, F.-E., Density Functional Studies on Palladium-Catalyzed Suzuki-Miyaura Cross-Coupling Reactions Assisted by N- or P-Chelating Ligands. Chem. Eur. J. 2008, 14 (14), 4426-4434; g) Jover, J.; Fey, N.; Purdie, M.; Lloyd-Jones, G. C.; Harvey, J. N., A computational study of phosphine ligand effects in Suzuki-Miyaura coupling. J. Mol. Catal. A 2010, 324 (1), 39-47; h) Kozuch, S.; Martin, J. M. L., What Makes for a Bad Catalytic Cycle? A Theoretical Study on the Suzuki-Miyaura Reaction within the Energetic Span Model. ACS Catal. 2011, 1 (4), 246-253; i) Kozuch, S.; Martin, J. M. L., What makes for a good catalytic cycle? A theoretical study of the SPhos ligand in the Suzuki-Miyaura reaction. Chem. Commun. 2011, 47 (17), 4935-4937; j) García-Melchor, M.; Braga, A. A. C.; Lledós, A.; Ujaque, G.; Maseras, F., Computational Perspective on Pd-Catalyzed C-C Cross-Coupling Reaction Mechanisms. Acc. Chem. Res. 2013, 46 (11), 2626-2634; k) Ortuño, M. A.; Lledós, A.; Maseras, F.; Ujaque, G., The Transmetalation Process in Suzuki-Miyaura Reactions: Calculations Indicate Lower Barrier via Boronate Intermediate. ChemCatChem 2014, 6 (11), 3132-3138; 1) Audran, G.; Brémond, P.; Marque, S. R. A.; Siri, D.; Santelli, M., Calculated linear free energy relationships in the course of the Suzuki-Miyaura coupling reaction Tetrahedron 2014, 70 (13), 2272-2279; m) Yaman, T.; Harvey, J. N., Suzuki-Miyaura coupling revisited: an integrated computational study. Faraday Discuss. 2019, 220 (0), 425-442.

7. Mechanistic studies about Ni-catalyzed S-M coupling: a) Zhang, K.; Conda-Sheridan, M.; R. Cooke, S.; Louie, J., N-Heterocyclic Carbene Bound Nickel(I) Complexes and Their Roles in Catalysis. Organometallics 2011, 30 (9), 2546-2552; b) Christian, A. H.; Müller, P.; Monfette, S., Nickel Hydroxo Complexes as Intermediates in Nickel-Catalyzed SuzukiMiyaura Cross-Coupling. Organometallics 2014, 33 (9), 2134-2137; c) Payard, P.-A.; Perego, L. A.; Ciofini, I.; Grimaud, L., Taming NickelCatalyzed Suzuki-Miyaura Coupling: A Mechanistic Focus on Boron-toNickel Transmetalation. ACS Catal. 2018, 8 (6), 4812-4823.

8.Grushin, V. V., Mixed Phosphine-Phosphine Oxide Ligands. Chem. Rev. 2004, 104 (3), 1629-1662.

9.Gaussian 09, R. A., M. J. Frisch, G. W. Trucks, H. B. Schlegel, G. E. Scuseria, M. A. Robb, J. R. Cheeseman, G. Scalmani, V. Barone, B Mennucci, G. A. Petersson, H. Nakatsuji, M. Caricato, X. Li, H. P. Hratchian, A. F. Izmaylov, J. Bloino, G. Zheng, J. L. Sonnenberg, M. Hada, M. Ehara, K. Toyota, R. Fukuda, J. Hasegawa, M. Ishida, T. Nakajima, Y. Honda, O. Kitao, H. Nakai, T. Vreven, J. A. Montgomery, Jr., J. E. Peralta, F. Ogliaro, M. Bearpark, J. J. Heyd, E. Brothers, K. N. Kudin, V. N. Staroverov, R. Kobayashi, J. Normand, K. Raghavachari, A. Rendell, J. C. Burant, S. S. Iyengar, J. Tomasi, M. Cossi, N. Rega, J. M. Millam, M. Klene, J. E. Knox, J. B. Cross, V. Bakken, C. Adamo, J. Jaramillo, R. Gomperts, R. E. Stratmann, O. Yazyev, A. J. Austin, R. Cammi, C. Pomelli, J. W. Ochterski, R. L. Martin, K. Morokuma, V. G. Zakrzewski, G. A. Voth, P. Salvador, J. J. Dannenberg, S. Dapprich, A. D. Daniels, O. Farkas, 
J. B. Foresman, J. V. Ortiz, J. Cioslowski, and D. J. Fox, Gaussian, Inc., Wallingford CT, 2009.

10.Zhao, Y.; Truhlar, D. G., The M06 suite of density functionals for main group thermochemistry, thermochemical kinetics, noncovalent interactions, excited states, and transition elements: two new functionals and systematic testing of four M06-class functionals and 12 other functionals. Theor. Chem. Acc. 2008, 120 (1), 215-241.

11.a) Hay, P. J.; Wadt, W. R., Ab initio effective core potentials for molecular calculations. Potentials for $\mathrm{K}$ to Au including the outermost core orbitals. J. Chem. Phys. 1985, 82 (1), 299-310; b) Hay, P. J.; Wadt, W. R.,
$\mathrm{Ab}$ initio effective core potentials for molecular calculations. Potentials for the transition metal atoms Sc to Hg. J. Chem. Phys. 1985, 82 (1), 270-283.

12.a) Tomasi, J.; Mennucci, B.; Cammi, R., Quantum Mechanical Continuum Solvation Models. Chem. Rev. 2005, 105 (8), 2999-3094; b) Cossi, M.; Scalmani, G.; Rega, N.; Barone, V., New developments in the polarizable continuum model for quantum mechanical and classical calculations on molecules in solution. J. Chem. Phys. 2002, 117 (1), 43-54.

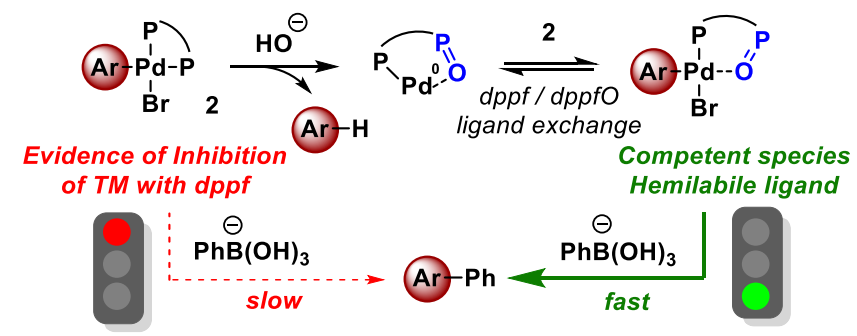

In situ oxidation of 1,1'-bis(diphenylphosphino)ferrocene (dppf) to the diphosphine monoxide (dppfO) accelerates the transmetalation step of the Suzuki-Miyaura coupling catalyzed by dppf-ligated Pd complexes. 